\title{
How short RNAs impact the human ribonuclease Dicer activity: putative regulatory feedback-loops and other RNA-mediated mechanisms controlling microRNA processing
}

\author{
Natalia Koralewska ${ }^{\dagger \dagger}$, Weronika Hoffmann ${ }^{2 \dagger}$, Maria Pokornowska ${ }^{1}$, Marek Milewski ${ }^{1}$, \\ Andrea Lipinska², Krystyna Bienkowska-Szewczyk², Marek Figlerowicz ${ }^{1,3}$ and \\ Anna Kurzynska-Kokorniak ${ }^{1 凶}$
}

IInstitute of Bioorganic Chemistry, Polish Academy of Sciences, Poznań, Poland; 2Intercollegiate Faculty of Biotechnology of the University of Gdansk and Medical University of Gdańsk, Gdansk, Poland; ${ }^{3}$ nstitute of Computing Science, Poznan University of Technology, Poznań, Poland

\begin{abstract}
Ribonuclease Dicer plays a pivotal role in RNA interference pathways by processing long double-stranded RNAs and single-stranded hairpin RNA precursors into small interfering RNAs (siRNAs) and microRNAs (miRNAs), respectively. While details of Dicer regulation by a variety of proteins are being elucidated, less is known about non-protein factors, e.g. RNA molecules, that may influence this enzyme's activity. Therefore, we decided to investigate the question of whether the RNA molecules can function not only as Dicer substrates but also as its regulators. Our previous in vitro studies indicated that the activity of human Dicer can be influenced by short RNA molecules that either bind to Dicer or interact with its substrates, or both. Those studies were carried out with commercial Dicer preparations. Nevertheless, such preparations are usually not homogeneous enough to carry out more detailed RNA-binding studies. Therefore, we have established our own system for the production of human Dicer in insect cells. In this manuscript, we characterize the RNA-binding and RNA-cleavage properties of the obtained preparation. We demonstrate that Dicer can efficiently bind singlestranded RNAs that are longer than $\sim 20$-nucleotides. Consequently, we revisit possible scenarios of Dicer regulation by single-stranded RNA species ranging from $\sim 10$ - to $~ 60$-nucleotides, in the context of their binding to this enzyme. Finally, we show that siRNA/miRNA-sized RNAs may affect miRNA production either by binding to Dicer or by participating in regulatory feedback-loops. Altogether, our studies suggest a broad regulatory role of short RNAs in Dicer functioning.
\end{abstract}

Key words: ribonuclease Dicer; miRNA processing; regulatory RNAs; regulation of Dicer activity; regulatory feedback-loops

Received: 01 June, 2016; revised: 27 June, 2016; accepted: 30 June, 2016; available on-line: 13 October, 2016

\section{INTRODUCTION}

One of the key components of RNA interference (RNAi) pathways is a multi-domain ribonuclease (RNase), called Dicer. Dicer is responsible for processing of double-stranded RNAs (dsRNAs) into small interfering RNAs (siRNAs) and excision of miRNAs from their hairpin precursors (pre-miRNAs) (Bernstein et al., 2001). In humans, miRNAs are the most abundant and as yet the best characterized group of small regulatory RNAs.
They have been found to regulate the expression of the majority of protein-coding genes through the miRNA pathway (Friedman et al., 2009). It has been also demonstrated that miRNAs play a very important role in the interplay between the host and the virus (Berkhout \& Haasnoot, 2006; Haasnoot \& Berkhout, 2006; Kurzynska-Kokorniak et al., 2009; Jackowiak et al., 2011a). Consequently, the cellular levels of miRNAs and other components of miRNA pathways must be tightly controlled. Deregulation of miRNA levels can initiate pathological processes, including carcinogenesis, neurodegenerative, immune system and rheumatic disorders (Calin \& Croce, 2006; Esquela-Kerscher \& Slack, 2006; Tili et al., 2008; Hebert \& De Strooper, 2009).

Human Dicer is a $\sim 220-\mathrm{kDa}$ protein consisting of an N-terminal domain homologous to the $\mathrm{DExD} / \mathrm{H}$ helicase, a domain of unknown function (DUF 283), the Piwi-Argonaute-Zwille (PAZ) domain, two RNase III domains (RNase IIIa and IIIb) and a C-terminal dsRNAbinding domain (dsRBD) (Bernstein et al., 2001; Zhang et al., 2002; Zhang et al., 2004; Macrae et al., 2006a; Macrae et al., 2006b). Comprehensive structural and biochemical analyses of Dicer have revealed the functions of its individual domains and allowed to propose mechanisms of Dicer functioning. According to the current model, miRNA and siRNA precursors are predominantly recognized by the PAZ domain (Yan et al., 2003; Ma et al., 2004; Zhang et al., 2004; Tian et al., 2014). In addition, RNA binding is supported by the dsRBD (Zhang et al., 2004; Ma et al., 2012; Wostenberg et al., 2012). The helicase domain interacts with the terminal loop of premiRNAs to align the substrate to the catalytic center of the enzyme for precise cleavage, and to discriminate between miRNA and siRNA precursors (Tsutsumi et al., 2011; Gu et al., 2012; Ma et al., 2012; Taylor et al., 2013). The helicase domain also plays an important regulatory role; it has been shown to be responsible for autoinhibition of Dicer (Ma et al., 2008) and to serve as a binding platform for auxiliary proteins (Bennasser \& Jeang, 2006; Daniels et al., 2009), as reviewed in KurzynskaKokorniak et al. (Kurzynska-Kokorniak et al., 2015). Two RNase III domains of Dicer form an intramolecular

Ue-mail: akurzyns@man.poznan.pl

tThese authors equally contributed to this work

Abbreviations: dsRNA, double-stranded RNA; hDicer, recombinant human Dicer protein; miRNA, microRNA; miR-Reg, an oligonucleotide with a sequence identical to a specific miRNA; pre-miRNA, pre-microRNA (microRNA precursor); RNAi, RNA interference; siRNA, small interfering RNA; ssRNA, single-stranded RNA 
dimer; each domain cleaves the opposing strand of the substrate. This way, $\sim 20$-base pair (bp) dsRNA products with characteristic 2-nucleotide (nt) 3' overhangs are generated. Finally, DUF283 has been found to be responsible for interactions with Dicer protein partners (Ota et al., 2013). Moreover, it has been demonstrated that the separate DUF283 domain of Dicer selectively binds single-stranded RNAs (ssRNAs) in vitro, and accelerates annealing of complementary nucleic acids (Kurzynska-Kokorniak et al., 2016).

Since the discovery of Dicer in 2000 (Bernstein et al., 2001), much attention has been placed on its role in RNAi/miRNA biogenesis pathways. Dicer is believed to participate in both, the cleavage of siRNA/miRNA precursors and the subsequent translocation of the generated duplexes to the RNA-induced silencing complex (RISC) (Gregory et al., 2005; Maniataki \& Mourelatos, 2005; Lee et al., 2006; MacRae et al., 2008; Noland et al., 2011). The substrate specificity of Dicer has been well characterized (Provost et al., 2002; Vermeulen et al., 2005; Lima et al., 2009; Chakravarthy et al., 2010; Tsutsumi et al., 2011; Feng et al., 2012). It has been demonstrated that Dicer binds ss- and dsRNAs with different affinities, depending on their sequence and length (Lima et al., 2009). In addition, RNA-binding and cleavage by Dicer have been shown to depend on the structure of the RNA substrates and the accessibility of their 3'- and 5'-ends (Vermeulen et al., 2005; Chakravarthy et al., 2010; Feng et al., 2012). Dicer activity is subjected to regulation by various protein and non-protein factors, as reviewed in Kurzynska-Kokorniak et al. (Kurzynska-Kokorniak et al., 2015). While the first group is relatively well characterized, still little is known about the non-protein factors that may regulate Dicer functioning. The latter group includes RNA molecules that bind to Dicer or to its substrates. For example, Dicer is supposed to interact with messenger RNAs (mRNAs) within so-called 'passive sites' (Rybak-Wolf et al., 2014). These sites are usually located in the coding sequences and the 3' untranslated regions of mRNAs that adopt stem-loop structures. Dicer has been shown to bind but not to cut passive sites. Therefore, passive binding has been proposed to serve either as an anchoring mechanism for the efficient assembly of Dicer-associated protein complexes or as a buffering system that controls the catalytic activity of Dicer by sequestering it from other targets. Interestingly, it has been demonstrated that viruses employ a similar strategy to mislead the host defense mechanisms (Lu \& Cullen, 2004; Andersson et al., 2005). For example, adenoviruses produce high amounts of long self-complementary transcripts that compete with endogenous Dicer substrates for binding to the enzyme. Thereby, other viral transcripts are protected from cleavage. In vitro studies conducted by our group have also indicated that the activity of human Dicer can be influenced by short RNA molecules that either bind to Dicer or interact with its substrates, or both (Tyczewska et al., 2011; KurzynskaKokorniak et al., 2013). Those studies were carried out with commercially available Dicers. However, we have found that commercial Dicer preparations are not homogeneous enough to carry out extended RNA-binding studies; therefore we have established our own system for the production of Dicer in insect cells.

In this manuscript, we report on the production of a new construct expressing a recombinant human Dicer protein (hDicer) in insect cells. To provide an increased efficiency of expression in the baculovirus system, the distance between the promoter and the translation start codon was shortened. The resulting construct lacked an extensive fragment of the 5' untranslated region of the hDicer transcript, which comprised additional AUG start codons. We further characterized the RNase and RNA-binding properties of the obtained preparations. We showed that our hDicer preparations process human pre-miRNAs with efficiency comparable to the commercial enzymes. We also demonstrated that the produced hDicer efficiently binds ssRNAs longer than $\sim 20$-nt. Then, we revisited the possible scenarios of regulation of hDicer activity by ssRNAs, ranging from $\sim 10$ - to $\sim 60$-nt, in the context of their binding to the enzyme. Finally, we demonstrated that siRNA/miRNA-sized ssRNAs may affect miRNA production either by binding to hDicer or by regulatory feedback-loops. Our findings strongly support observations that Dicer might be subjected to an RNA-dependent regulation in vivo.

\section{MATERIALS AND METHODS}

Oligonucleotides. Primers for hDicer cDNA cloning and RNA oligonucleotides used for cleavage assays were purchased from FutureSynthesis. Sequences of all oligonucleotides are listed in Table 1.

The 5'-end labeling of oligonucleotides. The 5'-32P oligonucleotide labeling by T4 Polynucleotide Kinase (Promega) was performed as described previously (Tyczewska et al., 2011; Kurzynska-Kokorniak et al., 2013). The ${ }^{32} \mathrm{P}-$ labeled oligonucleotides were purified by polyacrylamide gel electrophoresis (PAGE), in $8 \%$ denaturing gels, and resuspended in water to final concentration of approximately $10000 \mathrm{cpm} / \mu \mathrm{l}$.

Preparation of the recombinant human Dicer protein. To prepare hDicer, full-length cDNA encoding transcript variant 2 of DICER1 (NM_030621), cloned into $M l u I$ and NotI restriction sites of $\mathrm{p} \bar{B}$ lueScript vector, was purchased from GeneCopoeia. To obtain pBS-Dicer$\triangle 5$ 'UTR, a $238 \mathrm{bp}$ region corresponding to the DICER1 5'UTR, located upstream from the ATG selected as an initiation codon, was removed by PCR with the primer set: $\Delta 5$ 'UTR-F/ $\Delta 5$ 'UTR-R. The PCR product was subsequently cloned into Acc65I/NsiI restriction sites. The start codon was disrupted with ORF maintenance (using $\triangle \mathrm{ATG}-\mathrm{F} / \Delta 5^{\prime} \mathrm{UTR}-\mathrm{R}$ primer set), and the subsequent substitution in $\mathrm{pBS}-$ Dicer- $\Delta 5$ 'UTR was performed using Sall and NsiI restriction sites.

The recombinant baculovirus expressing $\mathrm{N}$-terminally His6-tagged hDicer was generated using the Bac-to-Bac Baculovirus Expression System (Invitrogen) according to the manufacturer's instructions. The target pFastBac HtB vector was prepared by cloning of the entire sequence of the ATG-less DICER1 gene into SalI and NotI restriction sites. The cDNA sequence of the modified Dicer was confirmed by sequencing. Next, the prepared plasmid was transformed into DH10Bac ${ }^{\mathrm{TM}} E$. coli competent cell, which yielded the recombinant bacmid DNA that was subsequently used for transfection of Sf9 insect cells using Cellfectin ${ }^{\circledR}$ (Invitrogen). The obtained baculovirus was used to produce hDicer in the Sf9 cells. For expression of hDicer, the Sf9 cells $\left(2 \times 10^{6} / \mathrm{ml}\right)$ were infected with the recombinant baculovirus at multiplicity of infection 1.0 (virus:cell ratio 1:1). Cells were collected after 2 days, precipitated and resuspended in ice-cold Ni100 lysis buffer (50 mM Tris- $\mathrm{HCl} \mathrm{pH} 7.5,100 \mathrm{mM} \mathrm{NaCl}, 10 \%$ glycerol and $0.5 \%$ Triton X-100) containing $1 \mathrm{x}$ protease inhibitor mix without EDTA (Roche). After $15 \mathrm{~min}$ incubation on ice, lysates were centrifuged at $17000 \times g$ for $10 \mathrm{~min}$ at $4^{\circ} \mathrm{C}$. The supernatant was incubated on a rotator with nickel-nitrilo triacetic agarose beads 
Table 1. The list of oligonucleotides used in this study

\begin{tabular}{|c|c|}
\hline Name & sequence $\left(5^{\prime} \rightarrow 3^{\prime}\right)$ \\
\hline$\Delta 5^{\prime} \mathrm{UTR}-\mathrm{F}$ & GGGGTACCGTCGACATGAAAAGCCCTGCTTTG \\
\hline$\Delta 5^{\prime} \mathrm{UTR}-\mathrm{R}$ & GGCGACATAGCAAGTCATAATGAGAACCTGGTG \\
\hline$\Delta$ ATG-F & ACGCGTCGACGAAAAGCCCTGCTITG \\
\hline RNA12 & AGCUUAUCAGAC \\
\hline RNA14 & GGGUACCACCAGAA \\
\hline RNA22 (miR-33a-3p) & CAAUGUUUCCACAGUGCAUCAC \\
\hline RNA32 & GUGCAUUGUAGUUGCAUUGCAUGUUCUGGUCA \\
\hline RNA42 & GGGAGAAUCAUAAGUAGCCUCCCCCCAUGUUAACAGUUAGCC \\
\hline RNA52 & GGGAGAAUCAUAAGUAGCCCCUCGUUCACUCCCCCCAUGUUAACAGUUAGCC \\
\hline RNA62 & UAGCAGCACGUAAAUAUUGGCGUUAAGAUUCUAAAAUUAUCUCCAGUAUUAACUGUGCUGCU \\
\hline pre-mir-16-1 & UAGCAGCACGUAAAUAUUGGCGUUAAGAUUCUAAAAUUAUCUCCAGUAUUAACUGUGCUGCUGAA \\
\hline pre-mir-21 & AGCUUAUCAGACUGAUGUUGACUGUUGAAUCUCAUGGCAACACCAGUCGAUGGGCUGU \\
\hline pre-mir-33a & GUGCAUUGUAGUUGCAUUGCAUGUUCUGGUGGUACCCAUGCAAUGUUUCCACAGUGCAUC \\
\hline pre-mir-210 & GCCCCUGCCCACCGCACACUGCGCUGCCCCAGACCCACUGUGCGUGUGACAGCGGCUG \\
\hline Reg-21-5p (miR-21-5p) & UAGCUUAUCAGACUGAUGUUGA \\
\hline Reg-21-3p (miR-21-3p) & CAACACCAGUCGAUGGGCUGU \\
\hline Reg-33a-5p (miR-33a-5p) & UGUCAUUGUAGUUGCAUUGCA \\
\hline Reg-33a-3p (miR-33a-3p) & CAAUGUUUCCACAGUGCAUCAC \\
\hline
\end{tabular}

(Ni-NTA, Qiagen) that were pre-washed with Ni100 buffer (resin:batch ratio 1:5). After $14 \mathrm{~h}$ incubation at $4^{\circ} \mathrm{C}$, the beads were packed into a column and successively washed with 10 resin volumes of Ni100 buffer and 10 resin volumes of Ni100 buffer supplemented with $10 \mathrm{mM}$ of imidazole. The bound hDicer was eluted with 3.33 resin volumes of Ni100 buffer containing $250 \mathrm{mM}$ imidazole. The fraction collected was loaded onto Amicon filters (Milipore) and the buffer was exchanged for Q100 (20 mM Tris- $\mathrm{HCl}$ pH 7.5, $100 \mathrm{mM}$ $\mathrm{NaCl}, 10 \%$ glycerol). Next, the sample was applied onto HiTrap Q HP column (GE Healthcare) equilibrated with Q100 buffer. The column was consecutively washed with 5 volumes of Q100 buffer and 5 volumes of Q200 buffer (buffer Q100 containing $200 \mathrm{mN} \mathrm{NaCl}$ ). The protein was eluted with 5 column volumes of buffer Q450 (buffer Q100 containing $450 \mathrm{mN} \mathrm{NaCl}$ ), and collected in $0.5 \mathrm{ml}$ fractions. Based on the results from SDSpolyacrylamide gel electrophoresis (PAGE) analysis followed by Coomassie Blue staining, the fractions of the highest purity were identified and pooled. Amicon filters (Milipore) were used for buffer exchange and for protein concentration. hDicer preparations were stored in $20 \mathrm{mM}$ Tris- $\mathrm{HCl} \mathrm{pH} 7.5,50 \mathrm{mM} \mathrm{NaCl}, 30 \%$ glycerol, at $-80^{\circ} \mathrm{C}$.

hDicer immunoblot analysis. The protein suspensions were analyzed by SDS-PAGE followed by immunoblotting. For immunoblotting, two types of antibod- ies were used: mouse monoclonal (13D6) against human Dicer (Abcam) or rabbit polyclonal against the His6 tag (Abcam). Immunoreactive proteins were visualized using horseradish peroxidase (HRP) conjugates and enhanced chemiluminescence (ECL) reagent.

hDicer binding assay. The ability of hDicer to bind ssRNA was tested by an electrophoretic mobility shift assay (EMSA). All reactions were carried out in a final volume of $10 \mu \mathrm{l}$. hDicer $(500 \mathrm{nM}$, unless stated otherwise) or $1 \mathrm{U}$ of commercially available enzyme (Ambion/GenLantis/Invitrogen) was added to 10000 cpm of ${ }^{32} \mathrm{P}$-labeled RNA and incubated in a binding buffer (250 mM NaCl, $20 \mathrm{mM}$ Tris-HCl, $\mathrm{pH}$ 7.5) for $30 \mathrm{~min}$ on ice. After incubation, $2 \mu \mathrm{l}$ of $60 \%$ glycerol with $0.04 \%$ bromophenol and $0.04 \%$ xylenecyanol were added and the samples were separated on $5 \%$ native polyacrylamide gel at $4^{\circ} \mathrm{C}$ in $1 \times \mathrm{TBE}$ running buffer. The data were collected using a Fujifilm FLA5100 Fluorescent Image Analyzer and quantified using MultiGauge 3.0 software (Fujifilm).

hDicer cleavage assay. To investigate hDicer RNase activity, $10000 \mathrm{cpm}$ of ${ }^{32} \mathrm{P}$-labeled pre-miRNA substrate was incubated with $200 \mathrm{nM}$ hDicer preparation for $2 \mathrm{~h}$ at $37^{\circ} \mathrm{C}$, unless stated otherwise. The assay was performed in a final volume of $10 \mu \mathrm{l}$, in the standard reaction buffer (250 $\mathrm{mM} \mathrm{NaCl}, 2.5 \mathrm{mM} \mathrm{MgCl}_{2}$ and $20 \mathrm{mM}$ Tris-HCl, $\mathrm{pH}$ 7.5). In addition, a reaction mixture without hDicer added was prepared as a control. Furthermore, in controls 
including EDTA, the reaction buffer was supplemented with the chelating agent to the final concentration of $50 \mathrm{mM}$. All reactions involving commercially available hDicers were carried out in the abovementioned buffer using $1 \mathrm{U}$ of the enzyme. The applied incubation conditions were the same as for the tested preparations of hDicer. The reactions were stopped by the addition of 1 volume of $8 \mathrm{M}$ urea loading buffer and heating for $5 \mathrm{~min}$ at $95^{\circ} \mathrm{C}$; the samples were separated on a $15 \%$ polyacrylamide/8 M urea gel. The data were collected using a Fujifilm FLA-5100 Fluorescent Image Analyzer and quantified using MultiGauge 3.0 software (Fujifilm).

hDicer cleavage inhibition assay. To test the influence of the selected oligonucleotides on hDicer RNase activity, standard reactions of pre-miRNA cleavage were performed (in a final volume of $10 \mu \mathrm{l}$ ). For each oligonucleotide, three reactions were prepared with the same amount of hDicer (200 $\mathrm{nM})$ and pre-miRNA (10000 $\mathrm{cpm}, \sim 1 \mathrm{pmol})$ and various amounts of the tested oligonucleotides. The molar ratio of pre-miRNA to oligonucleotide was as follows: 1:1, 1:10, and 1:100. Moreover, two reaction mixtures were prepared as controls: the first one without oligonucleotide added, and the sec-

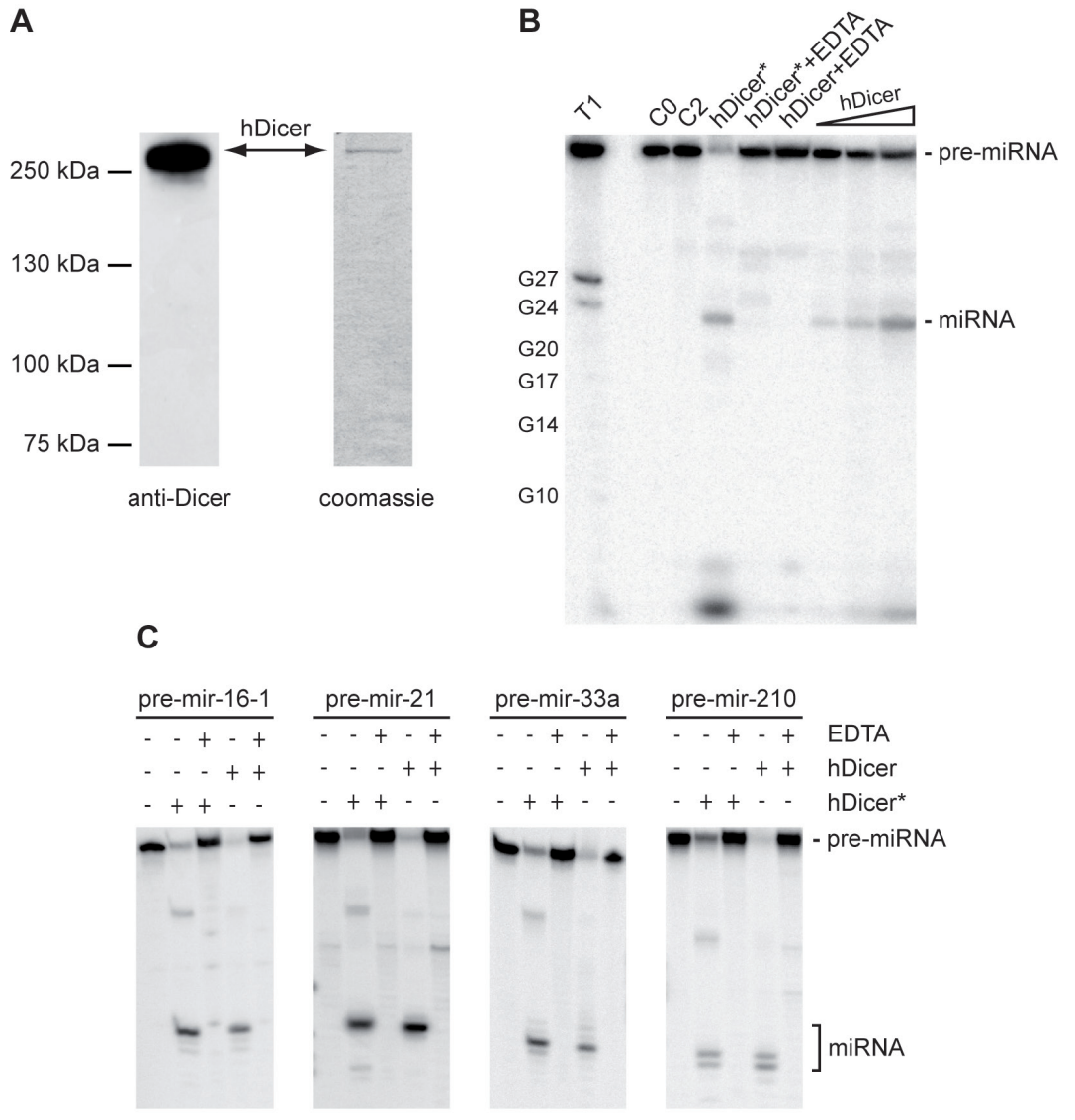

Figure 1. Characterization of the two-step purified hDicer.

(A) PAGE analysis of the hDicer preparation. The polyhistidine-tagged hDicer protein was expressed in the Baculovirus Expression System, purified by $\mathrm{Ni}^{2+}$ affinity chromatography followed by ion exchange chromatography, and analyzed by SDS-PAGE followed by Western blotting with anti-Dicer antibody (left), or Coomassie Blue staining (right). The band corresponding to hDicer is indicated. (B) The effect of increasing hDicer concentration on miRNA formation. The ${ }^{32}$ P-labeled pre-mir-21 was incubated with increasing amounts of the tested hDicer preparation $(1,2.5$ and $5 \mu \mathrm{l}$; represented by a triangle) or with a commercially available hDicer ( $h$ Dicer $\left.^{*}, 1 \mathrm{U}\right)$, and analyzed by denaturing PAGE. CO and $\mathrm{C} 2$ - controls incubated without hDicer for $0 \mathrm{~h}$ and $2 \mathrm{~h}$, respectively; $h D_{i c e r}^{*} / h D i c e r+E D T A-a$ reaction carried out with either a commercial enzyme or hDicer, in a buffer supplemented with 50 mM EDTA; T1 - Gladder generated with RNase T1. (C) Comparison of the hDicer cleavage activity on different pre-miRNAs. The ${ }^{32} \mathrm{P}$-labeled pre-miRNA, as indicated, was incubated with the tested hDicer preparation or with a commercially available enzyme ( $h D i c e r *)$. The presence of hDicer/hDic$\mathrm{er}^{*}$ and supplementation of the reaction buffer with $50 \mathrm{mM}$ EDTA are indicated with (+). ond without hDicer. All reactions were carried out in a standard reaction buffer and were incubated for $2 \mathrm{~h}$ at C. In addition, in experiments involving miR-regulathe buffer lacking $\mathrm{Mg}^{2+}$ ions. After that time, $\mathrm{Mg}^{2+}$ ions were added to induce hDicer cleavage and all samples were further incubated for $2 \mathrm{~h}$ at $37^{\circ} \mathrm{C}$. The reactions were stopped by addition of 1 volume of $8 \mathrm{M}$ urea loadwere separated on a $15 \%$ polyacrylamide/8 M urea gel. The data were collected using a Fujifilm FLA-5100 Fluorescent Image Analyzer and quantified using MultiGauge (Fujifilm). The efficiency of miRNA proin the control reaction, without the oligonucleotide.

Annealing assay assisted by hDicer. The pre-miRNA and oligonucleotide complex formation was using an electrophoretic mobility shift assay EMSA). The specific pair of RNAs (pre-miRNA and $(200 \mathrm{nM})$ in a binding buffer $(250 \mathrm{mM} \mathrm{NaCl}, 20 \mathrm{mM}$ $15 \mathrm{~min}$ at $37^{\circ} \mathrm{C}$. In the control reactions, no oligonucleotide was added. The reactions were stopped by the addition of SDS to a final concentration of $0.2 \%$ and separated by native gel electrophoresis on a $12 \%$ polyacrylamide gel. As a molecular mass ladder, the ${ }^{32} \mathrm{P}$-labeled premiRNA (10000 cpm, 1 pmol,) and the indicated oligonucleotide $(100 \mathrm{pmol})$ were mixed in a binding buffer, heated for $3 \mathrm{~min}$ at $95^{\circ} \mathrm{C}$, and then slowly cooled to $37^{\circ} \mathrm{C}$, to facilitate annealing. The data were collected using a Fujifilm FLA-5100 Fluorescent Image Analyzer and quantified using MultiGauge 3.0 software (Fujifilm).

Bioinformatic analysis. The predictions of RNA structure were performed using servers from the RNAstructure Web Servers family (Bellaousov et al. 2013): the bifold server (Mathews et al. 1999a; Reuter and Mathews 2010) and the Fold server (Mathews et al. 1999b; Reuter \& Mathews 2010) with default set of input parameters for each structure prediction.

\section{RESULTS AND DISCUSSION}

\section{Influence of the homogeneity of the recombinant human Dicer on its RNA-cleavage and RNA- binding properties}

In 2002, two research groups independently reported in the back-to-back articles the production and characterization of hDicer (Provost et al., 2002; Zhang et al., 2002). Both groups 
used the Baculovirus Expression System to obtain hDicer in insect cells. Since then, this enzyme has been successfully produced by many research groups (Ma et al., 2008; Lima et al., 2009). Preparations of hDicer are also commercially available. Our previous studies focusing on the regulation of the hDicer cleavage activity by short RNA molecules were carried out with commercial enzymes (Tyczewska et al., 2011; Kurzynska-Kokorniak et al., 2013). While we found them appropriate for assays based on pre-miRNA cleavage reactions, they do not seem to be suitable for detailed RNA-binding studies. Under the applied conditions, the commercial hDicer preparations that we used did not form stable complexes with premiRNAs. Therefore, we established our own system for the production of hDicer in insect cells (for details see Materials and Methods). Based on the procedure reported by Provost et al., we initially applied a one-step purification strategy involving $\mathrm{Ni}^{2+}$ affinity chromatography (Provost et al., 2002). The hDicer preparation obtained (Supplementary Fig. S1A) was assayed for its RNase activity. We carried out two sets of cleavage assays. In the first set, ${ }^{32} \mathrm{P}$-labeled pre-mir-21 was incubated with increasing amounts of the hDicer preparation (1, 2.5 and $5 \mu \mathrm{l}$ ) for $2 \mathrm{~h}$ at $37^{\circ} \mathrm{C}$. Two control reactions without hDicer were also carried out to test the integrity of the substrate before the reaction was started and after it was completed. To verify whether the observed cleavage was the result of the $\mathrm{Mg}^{2+}$-dependent RNase activity of hDicer, an additional control reaction contained the hDicer preparation and $50 \mathrm{mM}$ EDTA. To assess specificity and efficiency of the preparation obtained, a reaction with a commercially available hDicer was carried out. The second set of reactions involved timedependent assays. Reaction mixtures contained $5 \mu$ l of hDicer and ${ }^{32}$ P-labeled pre-mir-21, and were incubated for $10 \mathrm{~min}, 30 \mathrm{~min}, 1.5 \mathrm{~h}, 3 \mathrm{~h}$ and $5 \mathrm{~h}$ at $37^{\circ} \mathrm{C}$. All reaction mixtures were separated by denaturing PAGE and visualized by phosphorimaging. In general, the data collected indicated that the hDicer preparation after one-step purification by $\mathrm{Ni}^{2+}$ affinity chromatography displayed the RNase activity and generated the specific miRNA products. However, an increase in the hDicer concentration (Supplementary Fig. S1B at www.actabp. $\mathrm{pl}$ ), and/or incubation for longer than $30 \mathrm{~min}$ (Supplementary Fig. S1B, C at www.actabp.pl), caused the level of miRNA product to be decreased. Because in all of these reactions we also observed a rapid decrease in the substrate, we concluded that the tested hDicer preparation contained some factor/s that might degrade both, the substrate and the product. Alternatively, the enzyme processed pre-miRNAs very efficiently, but resultant miRNAs were further digested by an as yet unknown factor/s. Addition of the commercial RNase-inhibitor cocktails did not significantly reduce degradation of the substrates and products (data not shown). We further assayed the hDicer preparation for the RNA-binding capacity. To this end, ${ }^{32} \mathrm{P}$-labeled pre-mir-21 was incubated with increasing amounts of the hDicer preparation. Reaction mixtures were separated by native PAGE and visualized by phosphorimaging (Supplementary Fig. S1D at www.actabp.pl). We found that in addition to a band corresponding to a putative hDicer-pre-miRNA complex, smeared bands and well-complexes (material that did not migrate out of the wells) were also formed. The comparison of the homogeneity of the obtained hDicer preparation and commercial enzymes showed that they were purified to a similar level (see Supplementary Fig. S1A and Supplementary Fig. S2 at www.actabp.pl). We repeated the RNA-cleavage and RNA-binding assays with different batches of the one-step purified hDicer; however, we did not obtain reproducible results. Thus, the hDicer preparation was subjected to further purification involving ion-exchange chromatography. The twostep purified hDicer (Fig. 1A) was tested for its RNase and RNA-binding capacities, according to the above protocols. Results of these assays are shown in Fig. 1B. The data collected revealed that an increase in hDicer concentration was accompanied by an increase in the miRNA product. In the next experiment, we evaluated the RNase activity of the two-step purified hDicer using different pre-miRNA substrates; namely, pre-mir-16-1, $-21,-33 \mathrm{a}$ and -210 . In each reaction set, a ${ }^{32} \mathrm{P}-\mathrm{labeled}$ pre-miRNA was incubated with $5 \mu \mathrm{l}$ of hDicer for $2 \mathrm{~h}$ at $37^{\circ} \mathrm{C}$. Control reactions were carried out with a commercial enzyme. Another two control reactions contained either a commercial hDicer or our two-step purified hDicer preparation, and $50 \mathrm{mM}$ EDTA (Fig. 1C). These experiments indicated that the obtained preparation processed pre-mir-16-1, -21, 33a and -210 with almost equal efficiencies. We also found that the efficiency of miRNA production by our preparation was comparable to the efficiency of miRNA production by commercial enzymes. Finally, to evaluate the amount of the enzyme optimal for the RNA cleavage assays, ${ }^{32} \mathrm{P}$-labeled pre-mir-21 was incubated with increasing amounts of hDicer (20-650 $\mathrm{nM}$ ) for $2 \mathrm{~h}$ at $37^{\circ} \mathrm{C}$. Protein concentration was estimated by using the Bradford reagent, with BSA as a standard. Based on results obtained from three independent experiments, we calculated the cleavage efficacy (the ratios between the substrate (pre-mir-21) and the product

\section{A}
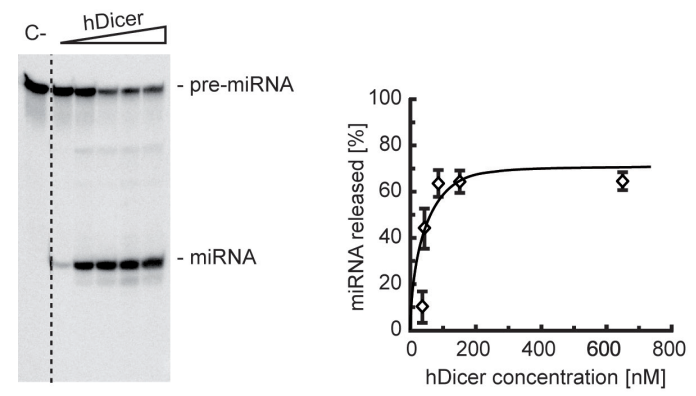

B
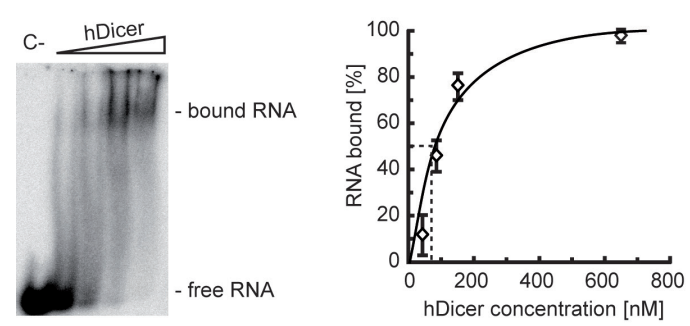

Figure 2. RNA-cleavage and RNA-binding properties of the twostep purified hDicer.

(A) Quantitative analysis of pre-miRNA processing by hDicer. The 32P-labeled pre-mir-21 was incubated in the absence $(C-)$ or presence of hDicer $(20,40,80,160,650 \mathrm{nM}$; represented by a triangle) and analyzed by denaturing PAGE. The fraction of miRNA released by hDicer was determined and fit as a function of the protein concentration. Error bars represent standard deviation of three independent experiments. (B) Determination of the equilibrium dissociation constant of the hDicer and pre-miRNA complex. The ${ }^{32} \mathrm{P}-$ labeled pre-mir-21 was incubated in the absence $(C-)$ or presence of hDicer $(20,40,80,160,650 \mathrm{nM}$; represented by a triangle) and analyzed by EMSA. The fraction of bound RNA was determined and fit as a function of hDicer concentration. Error bars represent standard deviation of three independent experiments. 


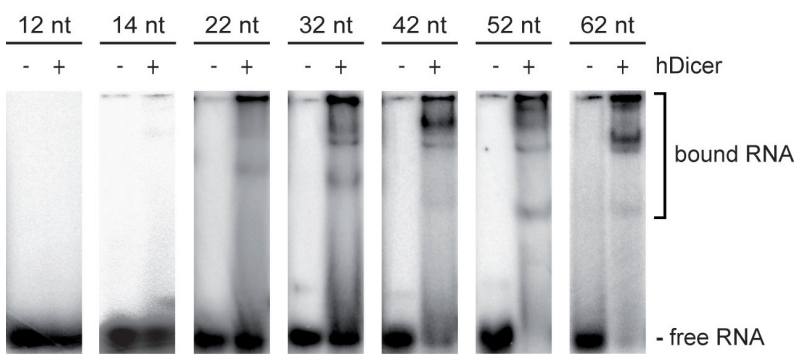

Figure 3. Binding between hDicer and single-stranded RNAs of different length.

The ssRNA-binding capacity of hDicer was tested by EMSA. The 32P-labeled oligonucleotides (RNA12, RNA22, RNA32, RNA42, RNA52, RNA62) were incubated in the absence or presence of hDicer, denoted (-) and (+), respectively. The length of the tested RNAs is given above each panel.

(miR-21)) for each reaction. The average percentage of the product released was plotted against the molar concentrations of hDicer. We found that the maximum efficacy of the substrate cleavage was achieved at a hDicer concentration of $\sim 150 \mathrm{nM}$ (Fig. 2A). In addition, we attempted to determine the $K_{\mathrm{d}}$ value for the hDicer and pre-miRNA complex using EMSA. As shown in Fig. 2B, the $K_{\mathrm{d}}$ value for the hDicer and pre-mir-21 complex was $80 \pm 5.6 \mathrm{nM}$, which is of the same order of magnitude as previously reported for hDicer and other pre-miRNAs (Ma et al., 2008; Feng et al., 2012).

\section{Binding between hDicer and single-stranded RNAs of different length}

Our previous studies showed that the activity of hDicer can be affected by short RNA molecules binding to the enzyme, substrate or both (Tyczewska et al., 2011; Kurzynska-Kokorniak et al., 2013; Kurzynska-Kokorniak et al., 2015). In the pool of the investigated ssRNAs there were species ranging from 12- to 62-nt. To explore which of the tested ssRNAs are able to interact with hDicer, we carried out binding assays involving 12-, 14-, 22-, 32-, 42-, 52- and 62-nt-long ssRNAs. The ${ }^{32} \mathrm{P}-$ labeled ssRNAs were incubated with or without hDicer for $30 \mathrm{~min}$ at $4^{\circ} \mathrm{C}$ and analyzed by native PAGE. The
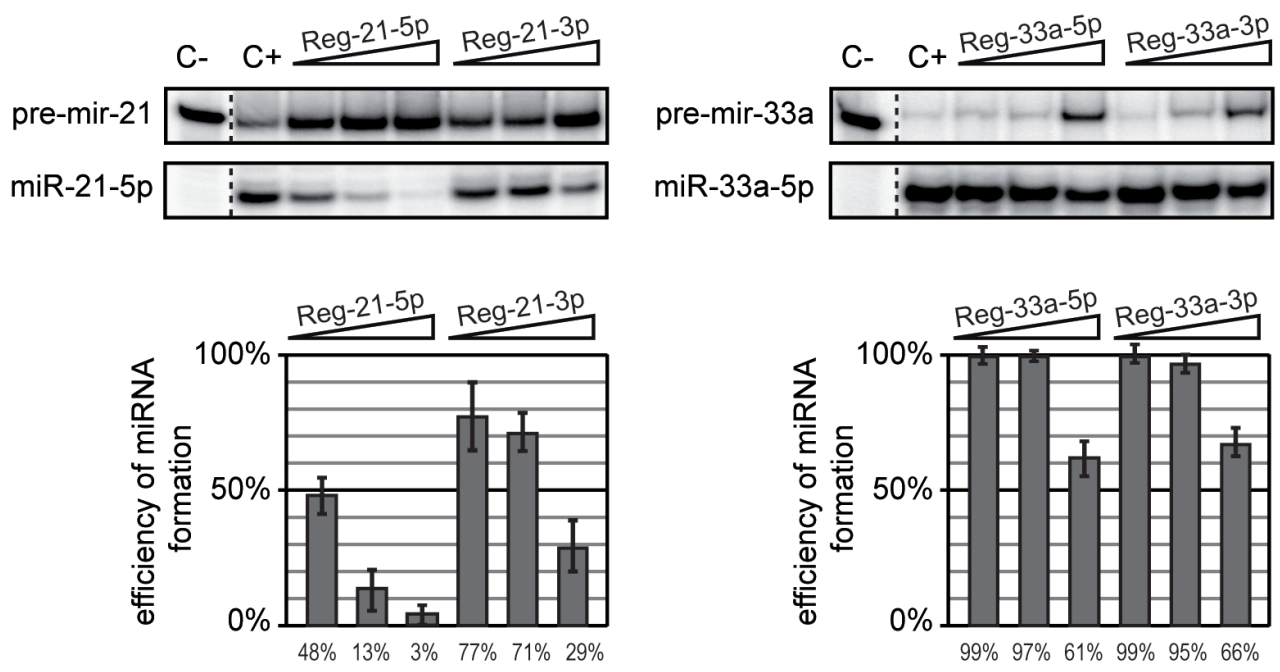

Figure 4. Influence of $\sim 20$-nt miR-regulators on hDicer activity.

The ${ }^{32}$-labeled pre-miRNA (pre-mir-21 or pre-mir-33a) was incubated with hDicer in the presence of the indicated miR-regulator, and analyzed by denaturing PAGE. Control reactions lacked the enzyme and miR-regulator ( $C$-) or miR-regulator only $(C+)$. Triangles represent increasing amounts of a miR-regulator (pre-miRNA and miR-regulator molar ratios of 1:1, 1:10, and 1:100). Diagrams show the average efficiency of miRNA production in comparison to $C+$; error bars represent the standard deviation from three independent experiments. 
transcripts, in this way promoting their processing. Considering all the above information, we asked the question whether siRNA/miRNA-sized ssRNAs might selectively influence production of the individual miRNAs by hDicer. To answer this problem, the hDicer cleavage assays involving either pre-mir-21 or pre-mir-33a were performed. Each of these precursors gives rise to two functional miRNAs (miRNA-5p and miRNA-3p), whose biological functions have been already well characterized (Doberstein et al., 2014; Pink et al., 2015). In the assays performed, we focused on production of miRNA-5p. As putative regulators of either pre-mir-21 or pre-mir-33a cleavage by hDicer, we used oligonucleotides identical with miRNAs (miRNA-5p and miRNA-3p), originating from these two precursors. We named them accordingly: Reg-5p and Reg-3p, while both were called miR-regulators. Reaction mixtures contained fixed concentrations of the 5' end-labeled pre-miRNA and of hDicer, and only the amount of the miR-regulators was altered as follows: $1: 1,1: 10,1: 100$, molar ratios of pre-miRNA to either Reg-5p or Reg-3p. In addition, two control reactions
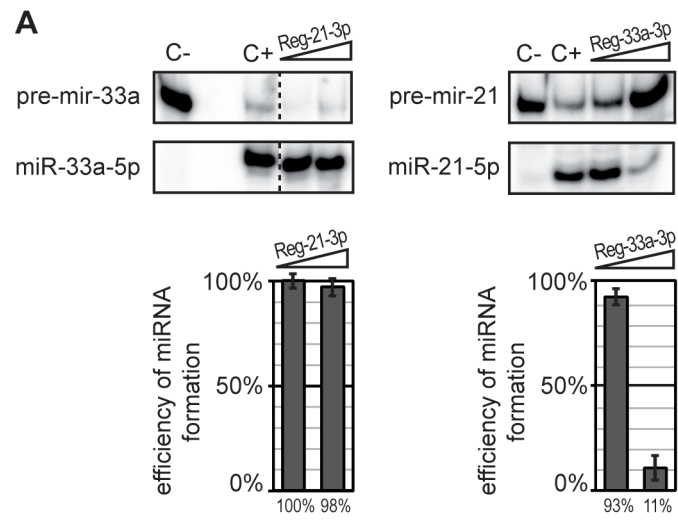

C
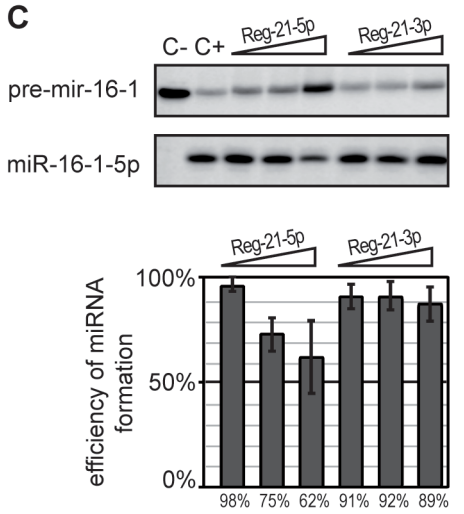

were always run, a reaction without hDicer (C-) and a reaction without a miR-regulator $(\mathrm{C}+)$. To allow interaction among pre-miRNA, miR-regulator and hDicer before cleavage, all mixtures were pre-incubated for $15 \mathrm{~min}$ in a buffer lacking $\mathrm{Mg}^{2+}$ ions. After that time, $\mathrm{Mg}^{2+}$ ions were added to induce hDicer cleavage and all samples were further incubated for $2 \mathrm{~h}$ at $37^{\circ} \mathrm{C}$. The amount of the pre-miRNA and miRNA-5p was determined for each reaction and the efficiency of miRNA-5p production in the presence or absence of Reg-5p/Reg-3p was calculated. The influence of a miR-regulator on miRNA production was expressed as a percentage, with $100 \%$ defined as the miRNA-5p production in reactions conducted without a miR-regulator. The collected results are presented in Fig. 4. In general, we found that all miR-regulators, at the highest concentrations used, affected the corresponding miRNA-5p production. In the case of the premir-21 cleavage assay, we noticed that Reg-21-5p influenced formation of miR-21-5p more efficiently than did Reg-21-3p. Even at the lowest concentration used, Reg-21-5p reduced miR-21-5p production by $\sim 50 \%$. At the highest concentration used, Reg-21-5p almost completely repressed pre-mir-21 processing by hDicer, while at the same concentration, Reg-21-3p decreased production of miR-21-5p by $\sim 70 \%$ (Fig. 4, left panel). In the case of the pre-mir-33a cleavage assay, we did not observe a significant difference between inhibition potency of Reg-33a-5p and Reg-33a-3p; both regulators at low concentrations did not affect cleavage of pre-mir-33a. At the highest concentration used, both reduced miR-33a-5p production by $\sim 40 \%$ (Fig. 4 , right panel). To test the specificity of the regulators used, we prepared control reactions that contained pairs: pre-mir33a:Reg-21-3p and pre-mir-21:Reg$33 a-3 p$, at pre-miRNA to Reg-3p molar ratios of $1: 1$ and 1:100 (Fig. 5A). We found that Reg-21-3p, even at the highest concentration used, did not affect pre-mir-33a cleavage by hDicer. In contrast, Reg-33a-3p, at its highest concentration, reduced miR-21-5p formation by $\sim 90 \%$. Providing the fact that at the same concentration Reg$33 a-3 p$ decreased miR-33a-5p production by $\sim 40 \%$, it was an unexpected result. Based on our previous observations, summarized in (KurzynskaKokorniak et al., 2013), we hypothesized that Reg-33a-3p interacted with pre-mir-21. Indeed, a secondary structure predicted by the RNAstructure program, revealed that Reg-33a-3p could bind to pre-mir-21 (Fig. 5B), which was further confirmed by EMSA (data not shown). Interestingly, results of our experiments are in line with the observations of Tang et al., who demonstrated that one miRNA can control the biogenesis of other miRNAs by base-pairing with their precursors (Tang et al., 2011). The authors showed that in mouse, miR-709 directly binds to a 19-nt 
miR-709 recognition element on primary transcript primiR-15a/16-1, in this way preventing its processing into pre-mir-15a/16-1 and in consequence preventing formation of mature miR-15a/16-1.

Data shown in Fig. 4 and Fig. 5A, B suggested that some miRNAs might act as specific regulators; as is the case of Reg-21-3p. To test whether Reg-21-3p might be a specific regulator, we performed another set of control experiments involving pre-mir-16-1 and either Reg-21-5p or Reg-21-3p (Fig. 5C). The obtained results revealed that Reg-21-5p, at the highest concentration used, inhibited miR-16-1 production by $\sim 40 \%$, though both molecules do not share complementary sequences. At the same concentrations, Reg-21-3p only slightly influenced miR-16-1 production. These results further confirmed that Reg-21-3p might act as a specific inhibitor of miR-21-5p production. Very recently, we showed that hDicer and its DUF283 domain can accelerate annealing of complementary ssRNAs (Kurzynska-Kokorniak et al., 2016). Given that all cleavage reactions were preceded by $15 \mathrm{~min}$ incubation with hDicer and they included complementary RNAs (pre-miRNA and the respective miR-regulator), we assumed that the characterized phenomenon might also apply to the performed pre-miRNA cleavage assays. Therefore, we monitored the effect of pre-incubation with hDicer, in the absence of $\mathrm{Mg}^{2+}$ ions, for pairs: pre-mir-21 and Reg-21-5p, pre-mir-21 and Reg-21-3p, pre-mir-33a and Reg-33a-5p, pre-mir-33a and Reg-33a-3p, at 1:100 molar ratio of pre-miRNA to miR-regulator. The results obtained are presented in Supplementary Fig. S3 (at www.actabp.pl). We found that Reg-21-3p efficiently base-paired with pre-mir-21, and that reaction was strongly accelerated by hDicer. Thus, these results suggested that Reg-21-3p might act as an in-cis-regulator of miR-21 production by binding with its precursor. Our preliminary in vitro experiments were restricted to a few miRNA cases. Thus, there is no doubt that more extensive in vitro and in cell culture studies are needed to confirm that an auto-regulatory loop between miRNA and pre-miRNA does exist.

We also found that in the case of the pair: pre-mir-21 and Reg-21-5p, the hDicer-assisted annealing was very inefficient (Supplementary Fig. S3). Likewise, we found that Reg-21-5p bound to hDicer with similar efficiency as other $\sim 20$-nt ssRNAs tested (Fig. 3 and data not shown). Thus, at present we cannot explain the mechanism underlying such high inhibitory potential of Reg21-5p and apparently more detailed studies are needed to elucidate the observed phenomenon. Finally, annealing was not detected for pairs: pre-mir-33a and Reg-33a$5 p$, pre-mir-33a and Reg-33a-3p (Supplementary Fig. S3 at www.actabp.pl). In addition, inhibition assays presented in Fig. 4 indicated that Reg-33a-5p/ -3p affected miR-33a-5p production only to a small degree. Thus, we deduced that the observed inhibition resulted from weak binding of Reg-33a-5p/ -3p to hDicer (Fig. 3; lane marked [22 $\mathrm{nt}$ ] represents the results of EMSA containing Reg-33a-3p and hDicer).

In conclusion, we postulate that all tested $\sim 20$-nt ssRNAs can, to some extent, interact with hDicer, thereby sequestering its cleavage activity. It has been reported that the efficiency of $\sim 20$-nt ssRNAs binding to Dicer strongly depends on their sequence (Lima et al., 2009). These observations of Lima et al. might, at least in part, explain different inhibitory potential presented by the four 20 -nt miR-regulators used, each having a different RNA sequence. In addition, we found that two miR-regulators, one identical with miR-21-3p and the other identical with miR-33a-3p, could act as an in-cis- and in-trans-inhibitor, respectively, of pre-mir-21 cleavage by hDicer.

\section{Different mechanisms of the hDicer activity regulation by short single-stranded RNAs}

Based on the data collected during our earlier and present studies, we can classify the mechanisms by which RNA oligonucleotides affect hDicer activity in vitro into two groups: (i) the mechanisms involving direct binding of oligonucleotides to hDicer and (ii) the mechanisms based on oligonucleotide interactions with hDicer substrates. i.e., pre-miRNAs (Tyczewska et al., 2011; Kurzynska-Kokorniak et al., 2013). The first group encompasses the in vitro selected RNA oligonucleotides (Tyczewska et al., 2011). Although these oligonucleotides form a relatively homogenous group of RNAs in terms of their length (42-62-nt ssRNAs, mostly 56-nt) and the structure (stem-loop), we found that they differ in their potential to inhibit pre-miRNA cleavage by hDicer due to the different affinities to this enzyme. Depending on whether they are cut by hDicer or not, we can classify them as competitive or allosteric inhibitors, respectively (Fig. 6, I). The second group involves RNAs that are capable of base-pairing with pre-miRNAs (KurzynskaKokorniak et al., 2013). As a consequence of interactions between the oligonucleotide and the pre-miRNA, the native structure of the latter is disturbed. The resultant complex of RNA oligonucleotide and pre-miRNA either is not recognized and digested by hDicer (Fig. 6, II and 6 , IIIa) or, when recognized and processed by hDicer, the pattern of pre-miRNA cleavage is altered and mature, functional miRNAs are not formed (Fig. 6, IIIb). The scenario presented in Fig. 6, II takes into consideration oligonucleotides that are too short to bind to hDicer (RNAs shorter than 20-nt, as shown in Fig. 3). However, they can selectively base-pair with singlestranded regions of the individual pre-miRNAs and act as specific inhibitors that preclude the formation of the corresponding miRNAs.

Some of the tested oligonucleotides could be assigned to both groups, thus we named them bifunctional inhibitors. Bifunctional inhibitors are recognized and bound by hDicer but they also contain sequences complementary to pre-miRNAs. We characterized several such inhibitors, including 56-nt long ATD_15.52, ATD_13.6 (Kurzynska-Kokorniak et al., 2013), ATD_15.2 (Supplementary Fig. S4 at www.actabp.pl) and $\sim 30$-nt long PCDH21_fr, and THAP4_fr (Supplementary Fig. S5). In the case of ATD_15.52, we found that this oligonucleotide competes with pre-mir-210 for binding to hDicer; thus it acts as a competitive inhibitor. After ATD_15.52 cutting by hDicer, its 5' fragment binds to the apical region of pre-mir-210 due to complementarity between their sequences and inhibits pre-miRNA processing (the scenario presented in Fig. 6, Ia). ATD_13.6 is also bound by hDicer, but it is not processed by this enzyme; thus we hypothesize that it acts as an allosteric inhibitor. In addition, ATD_13.6 base-pairs with pre-mir-210 and completely disturbs the native structure of the precursor. We found that the ATD_13.6 and pre-mir-210 complex is not processed by hDicer (the scenario presented in Fig. 6, IIIa) (Kurzynska-Kokorniak et al., 2013). Interestingly, we also identified in our collection an oligonucleotide named ATD_15.2 that hybridizes with pre-mir-210, and the resultant dimer is recognized and processed by hDicer. In this case, however, the pattern of pre-mir-210 cleavage is altered and the functional miR-210 is not produced (the scenario presented in Fig. 6, IIIb) (Sup- 


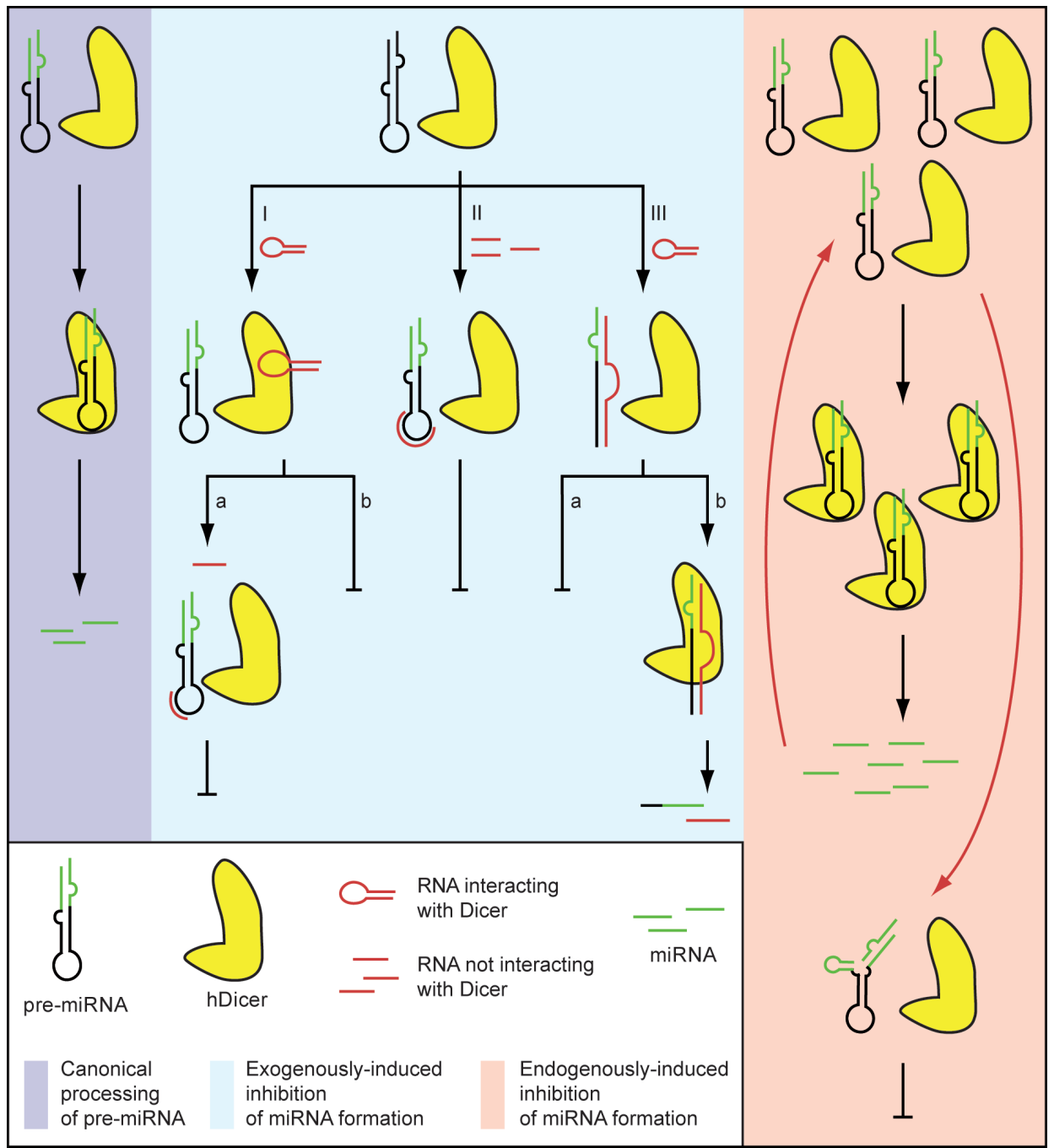

Figure 6. Proposed scenarios of short RNA-based regulation of hDicer cleavage activity.

A canonical pathway of pre-miRNA processing by hDicer (left) can be interfered by RNA oligonucleotides of various length. Oligonucleotides may affect hDicer activity by interacting with the enzyme $(I)$ or pre-miRNA (II, III), thus inhibiting miRNA formation $(I, I I, I I a)$ or altering the substrate cleavage pattern (IIIb). A possible mechanism of an auto-regulatory feedback loop (right).

plementary Fig. S4 at www.actabp.pl). In the set of bifunctional inhibitors there are also two $\sim 30$-nt ssRNAs identical with fragments of some transcripts, accordingly: PCDH21_fr, a 30-nt fragment of PCDH21 (H. sapiens protocadherin 21, potential calcium-dependent cell-adhesion protein) mRNA and THAP4_fr, a 35-nt fragment of THAP4 $(H$. sapiens THAP domain containing 4 protein, i.e., DNA and metal ion binding protein) mRNA (Tyczewska et al., 2011). Both oligonucleotides contain sequences complementary to pre-miR-210, but they can also interact with hDicer (Fig. 3). Inhibition assays carried out with pre-miR-210 and either PCDH21_fr or THAP4_fr are presented in Supplementary Fig. S5 (at www.actabp.pl), and the possible mechanism of inhibition displayed by these two oligonucleotides matches the scenario demonstrated in Fig. 6, IIIa.

Finally, we hypothesize that miRNAs that are produced at a high level, thus reaching a high local concentration, might interact with pre-miRNAs from which they derive (Fig. 6, right panel). Our observations are consistent with the earlier mentioned observations published by Pasquinelli et al., who have reported that let-7 miRNA maturation can be controlled by an autoregulatory loop between the let-7 miRNA and let-7 pri-miRNA (Zisoulis et al., 2012). Alternatively, miRNAs produced might target complementary pre-miRNAs other than their own precursors and, in this way, in trans repress their cleavage by Dicer (Fig. 5). Accordingly, Tang et al. have demonstrated that miR-709 can base-pair with pri-miR-15a/16-1, thereby preventing its processing into pre-mir-15a/16-1 (Tang et al., 2011).

All data presented in this manuscript were obtained in vitro and obviously it is not clear whether similar mechanisms of the Dicer activity regulation might exist in cells. Thus, the problem of RNA-based regulation of Dicer needs to be further explored in vivo. Nevertheless, growing evidence shows that the cytoplasm contains a wide spectrum of RNA molecules that hypothetically might interfere with miRNA biogenesis pathways Jackowiak et al., 2011b; Nowacka et al., 2012; Kurzynska-Kokorniak et al., 2015).

It is now clear that one of the most challenging issues of the biomedical field is designing and production of therapeutics that selectively interact with specific targets. Our data indicate that one can modulate the production of individual miRNAs by using specific RNA oligonucleotides. The application of such RNA molecules might be useful for the treatment of many diseases associated with the aberrant regulation of specific miRNA levels, like cancers, neurodegenerative diseases, and even infec- 
tious diseases caused by such dangerous viruses as HIV or HCV (Figlerowicz et al., 2003; Kurzynska-Kokorniak et al., 2009; Miazga et al., 2011; Jackowiak et al., 2012; Gorska et al., 2013; Jackowiak et al., 2014; Dutkiewicz et al., 2015; Belter et al., 2016).

\section{Acknowledgements}

This work was supported by the European Union Regional Development Fund within the PARENTBRIDGE Program of the Foundation for Polish Science [Pomost/2011-3/5 to A.K.K.]. This publication was also supported by the National Science Centre [Maestro 2012/04/A/NZ1/00056 to K.B.S.] and by the Polish Ministry of Science and Higher Education under the KNOW program.

\section{REFERENCES}

Andersson MG, Haasnoot PC, Xu N, Berenjian S, Berkhout B, Akusjarvi G (2005) Suppression of RNA interference by adenovirus virus-associated RNA. J Virol 79: 9556-9565. http://dx.doi. org/10.1128/JVI.79.15.9556-9565.2005

Bellaousov S, Reuter JS, Seetin MG, Mathews DH (2013) RNAstructure: web servers for RNA secondary structure prediction and analysis. Nucleic Acids Res 41: W471-W474. http://dx.doi.org/10.1093/ nar/gkt290

Belter A, Rolle K, Piwecka M, Fedoruk-Wyszomirska A, Naskret-Barciszewska MZ, Barciszewski J (2016) Inhibition of miR-21 in glioma cells using catalytic nucleic acids. Sci Rep 6: 24516. http://dx.doi. org/10.1038/srep24516

Bennasser Y, Jeang KT (2006) HIV-1 Tat interaction with Dicer: requirement for RNA. Retrovirology 3: 95 . http://dx.doi. org/10.1186/1742-4690-3-95

Berkhout B, Haasnoot J (2006) The interplay between virus infection and the cellular RNA interference machinery. FEBS Lett 580: 28962902. http://dx.doi.org/10.1016/j.febslet.2006.02.070

Bernstein E, Caudy AA, Hammond SM, Hannon GJ (2001) Role for a bidentate ribonuclease in the initiation step of RNA interference. Nature 409: 363-366. http://dx.doi.org/10.1038/35053110

Calin GA, Croce CM (2006) MicroRNA signatures in human cancers. Nat Rev Cancer 6: 857-866. http://dx.doi.org/10.1038/nrc1997

Chakravarthy S, Sternberg SH, Kellenberger CA, Doudna JA (2010) Substrate-specific kinetics of Dicer-catalyzed RNA processing. $J$ Mol Biol 404: 392-402. http://dx.doi.org/10.1016/j.jmb.2010.09.030

Daniels SM, Melendez-Pena CE, Scarborough RJ, Daher A, Christensen HS, El Far M, Purcell DF, Laine S, Gatignol A (2009) Characterization of the TRBP domain required for dicer interaction and function in RNA interference. BMC Mol Biol 10: 1471-2199. http:// dx.doi.org/10.1186/1471-2199-10-38

Doberstein K, Bretz NP, Schirmer U, Fiegl H, Blaheta R, Breunig C, Muller-Holzner E, Reimer D, Zeimet AG, Altevogt P (2014) miR$21-3 \mathrm{p}$ is a positive regulator of L1CAM in several human carcinomas. Cancer Lett 354: 455-466. http://dx.doi.org/10.1016/j.canlet.2014.08.020

Dutkiewicz M, Ojdowska A, Kuczynski J, Lindig V, Zeichhardt H, Kurreck J, Ciesiolka J (2015) Targeting highly structured RNA by cooperative action of siRNAs and helper antisense oligomers in living cells. PLoS One 10: e0136395. http://dx.doi.org/10.1371/journal.pone. 0136395

Esquela-Kerscher A, Slack FJ. 2006. Oncomirs - microRNAs with a role in cancer. Nat Rev Cancer 6:259-269. http://dx.doi.org/10.1038/ nrc1840

Feng Y, Zhang X, Graves P, Zeng Y (2012) A comprehensive analysis of precursor microRNA cleavage by human Dicer. RNA 18: 20832092. http://dx.doi.org/10.1261/rna.033688.112

Figlerowicz M, Alejska M, Kurzynska-Kokorniak A (2003) Genetic variability: the key problem in the prevention and therapy of RNAbased virus infections. Med Res Rev 23: 488-518. http://dx.doi. org/10.1002/med.10045

Friedman RC, Farh KK, Burge CB, Bartel DP. 2009. Most mammalian mRNAs are conserved targets of microRNAs. Genome Res 19:92-105. http://dx.doi.org/10.1101/gr.082701.108

Gorska A, Swiatkowska A, Dutkiewicz M, Ciesiolka J (2013) Modulation of p53 expression using antisense oligonucleotides complementary to the 5'-terminal region of $\mathrm{p} 53 \mathrm{mRNA}$ in vitro and in the living cells. PLoS One 8: e78863. http://dx.doi.org/10.1371/journal. pone.0078863

Gregory RI, Chendrimada TP, Cooch N, Shiekhattar R (2005) Human RISC couples microRNA biogenesis and posttranscriptional gene silencing. Cell 123: 631-640. http://dx.doi.org/10.1016/j. cell.2005.10.022

Gu S, Jin L, Zhang Y, Huang Y, Zhang F, Valdmanis PN, Kay MA. 2012. The loop position of shRNAs and pre-miRNAs is critical for the accuracy of dicer processing in vivo. Cell 151: 900-911. http:// dx.doi.org/10.1016/j.cell.2012.09.042

Haasnoot J, Berkhout B (2006) RNA interference: its use as antiviral therapy. Handb Exp Pharmacol: 117-150.

Hebert SS, De Strooper B (2009) Alterations of the microRNA network cause neurodegenerative disease. Trends Neurosci 32: 199-206. http://dx.doi.org/10.1016/j.tins.2008.12.003

Jackowiak P, Figlerowicz M, Kurzynska-Kokorniak A, Figlerowicz M (2011a) Mechanisms involved in the development of chronic hepatitis C as potential targets of antiviral therapy. Curr Pharm Biotechnol 12: $1774-1780$.

Jackowiak P, Kowala-Piaskowska A, Figlerowicz M, Alejska M, Malinowska N (2012) Evolution of hepatitis C virus hypervariable region 1 in chronically infected children. Virus Res 167: 380-384. http://dx.doi.org/10.1016/j.virusres.2012.05.005

Jackowiak P, Kuls K, Budzko L, Mania A, Figlerowicz M (2014) Phylogeny and molecular evolution of the hepatitis $C$ virus. Infect Genet Evol 21: 67-82. http://dx.doi.org/10.1016/j.meegid.2013.10.021

Jackowiak P, Nowacka M, Strozycki PM, Figlerowicz M (2011b) RNA degradome - its biogenesis and functions. Nucleic Acids Res 39: 7361-7370. http://dx.doi.org/10.1093/nar/gkr450

Kini HK, Walton SP (2007) In vitro binding of single-stranded RNA by human Dicer. FEBS Lett 581: 5611-5616. http://dx.doi. org/10.1016/j.febslet.2007.11.010

Kurzynska-Kokorniak A, Jackowiak P, Figlerowicz M, Figlerowicz M. (2009) Human- and virus-encoded microRNAs as potential targets of antiviral therapy. Mini Rev Med Chem 9: 927-937

Kurzynska-Kokorniak A, Koralewska N, Pokornowska M, Urbanowicz A, Tworak A, Mickiewicz A, Figlerowicz M (2015) The many faces of Dicer: the complexity of the mechanisms regulating Dicer gene expression and enzyme activities. Nucleic Acids Res 43: 4365-4380. http://dx.doi.org/10.1093/nar/gkv328

Kurzynska-Kokorniak A, Koralewska N, Tyczewska A, Twardowski T, Figlerowicz M (2013) A new short oligonucleotide-based strategy for the precursor-specific regulation of microRNA processing by Dicer. PLoS One 8: e77703. http://dx.doi.org/10.1371/journal. pone.0077703

Kurzynska-Kokorniak A, Pokornowska M, Koralewska N, Hoffmann W, Bienkowska-Szewczyk K, Figlerowicz M (2016) Revealing a new activity of the human Dicer DUF283 domain in vitro. Sci Rep 6: 23989. http://dx.doi.org/10.1038/srep23989

Lee Y, Hur I, Park SY, Kim YK, Suh MR, Kim VN (2006) The role of PACT in the RNA silencing pathway. EMBO J 25: 522-532. http://dx.doi.org/10.1038/sj.emboj.7600942

Lima WF, Murray H, Nichols JG, Wu H, Sun H, Prakash TP, Berdeja AR, Gaus HJ, Crooke ST (2009) Human Dicer binds short singlestrand and double-strand RNA with high affinity and interacts with different regions of the nucleic acids. J Biol Chem 284: 2535-2548. http://dx.doi.org/10.1074/jbc.M803748200

Lu S, Cullen BR (2004) Adenovirus VA1 noncoding RNA can inhibit small interfering RNA and MicroRNA biogenesis. J Virol 78: 1286812876. http://dx.doi.org/10.1128/JVI.78.23.12868-12876.2004

Ma E, MacRae IJ, Kirsch JF, Doudna JA (2008) Autoinhibition of human dicer by its internal helicase domain. J Mol Biol 380: 237-243. S0022-2836. http://dx.doi.org/10.1016/j.jmb.2008.05.005

Ma E, Zhou K, Kidwell MA, Doudna JA (2012) Coordinated activities of human dicer domains in regulatory RNA processing. J Mol Biol 422: 466-476. http://dx.doi.org/10.1016/j.jmb.2012.06.009

Ma JB, Ye K, Patel DJ (2004) Structural basis for overhang-specific small interfering RNA recognition by the PAZ domain. Nature 429: 318-322. http://dx.doi.org/10.1038/nature02519

Macrae IJ, Li F, Zhou K, Cande WZ, Doudna JA (2006a) Structure of Dicer and mechanistic implications for RNAi. Cold Spring Harb Symp Quant Biol 71: 73-80. http://dx.doi.org/10.1101/sqb.2006.71.042

MacRae IJ, Ma E, Zhou M, Robinson CV, Doudna JA (2008) In vitro reconstitution of the human RISC-loading complex. Proc Natl Acad Sci U S A 105: 512-517. http://dx.doi.org/10.1073/ pnas.0710869105

Macrae IJ, Zhou K, Li F, Repic A, Brooks AN, Cande WZ, Adams PD, Doudna JA (2006b) Structural basis for double-stranded RNA processing by Dicer. Science 311: 195-198. http://dx.doi. org/10.1126/science.1121638

Maniataki E, Mourelatos Z (2005) A human, ATP-independent, RISC assembly machine fueled by pre-miRNA. Genes Dev 19: 2979-2990. http://dx.doi.org/10.1101/gad.1384005

Mathews DH, Burkard ME, Freier SM, Wyatt JR, Turner DH (1999a) Predicting oligonucleotide affinity to nucleic acid targets. $R N A 5$ : 1458-1469

Mathews DH, Sabina J, Zuker M, Turner DH (1999b) Expanded sequence dependence of thermodynamic parameters improves prediction of RNA secondary structure. J Mol Biol 288: 911-940 
Miazga A, Hamy F, Louvel S, Klimkait T, Pietrusiewicz Z, Kurzynska-Kokorniak A, Figlerowicz M, Winska P, Kulikowski T (2011) Thiated derivatives of 2',3'-dideoxy-3'-fluorothymidine: synthesis, in vitro anti-HIV-1 activity and interaction with recombinant drug resistant HIV-1 reverse transcriptase forms. Antiviral Res 92: 57-63. http:// dx.doi.org/10.1016/j.antiviral.2011.05.012

Noland CL, Ma E, Doudna JA (2011) siRNA repositioning for guide strand selection by human Dicer complexes. Mol Cell 43: 110-121. http://dx.doi.org/10.1016/j.molcel.2011.05.028

Nowacka M, Jackowiak P, Rybarczyk A, Magacz T, Strozycki PM, Barciszewski J, Figlerowicz M (2012) 2D-PAGE as an effective method of RNA degradome analysis. Mol Biol Rep 39: 139-146. http:// dx.doi.org/10.1007/s11033-011-0718-1

Ota H, Sakurai M, Gupta R, Valente L, Wulff BE, Ariyoshi K, Iizasa H, Davuluri RV, Nishikura K. 2013. ADAR1 Forms a complex with Dicer to promote microRNA processing and RNA-induced gene silencing. Cell 153: 575-589. http://dx.doi.org/10.1016/j. cell.2013.03.024

Pink RC, Samuel P, Massa D, Caley DP, Brooks SA, Carter DR (2015) The passenger strand, miR-21-3p, plays a role in mediating cisplatin resistance in ovarian cancer cells. Gynecol Oncol 137: 143-151. http://dx.doi.org/10.1016/j.ygyno.2014.12.042

Provost P, Dishart D, Doucet J, Frendewey D, Samuelsson B, Radmark O (2002) Ribonuclease activity and RNA binding of recombinant human Dicer. EMBO J 21: 5864-5874

Reuter JS, Mathews DH (2010) RNAstructure: software for RNA secondary structure prediction and analysis. BMC_Bioinformatics 11: 1-9. http://dx.doi.org/10.1186/1471-2105-11-129

Rybak-Wolf A, Jens M, Murakawa Y, Herzog M, Landthaler M, Rajewsky N (2014) A Variety of dicer substrates in human and C. elegans. Cell 159: 1153-1167. http://dx.doi.org/10.1016/j.cell.2014.10.040

Tang R, Li L, Zhu D, Hou D, Cao T, Gu H, Zhang J, Chen J, Zhang CY, Zen K (2011) Mouse miRNA-709 directly regulates miRNA$15 \mathrm{a} / 16-1$ biogenesis at the posttranscriptional level in the nucleus: evidence for a microRNA hierarchy system. Cell Res 22: 504-515. http://dx.doi.org/10.1038/cr.2011.137

Taylor DW, Ma E, Shigematsu H, Cianfrocco MA, Noland CL, Nagayama K, Nogales E, Doudna JA, Wang HW (2013) Substrate-specific structural rearrangements of human Dicer. Nat Struct Mol Biol 20: 662-670. http://dx.doi.org/10.1038/nsmb.2564

Tian Y, Simanshu DK, Ma JB, Park JE, Heo I, Kim VN, Patel DJ (2014) A phosphate-binding pocket within the platform-PAZ-connector helix cassette of human Dicer. Mol Cell 53: 606-616. http:// dx.doi.org/10.1016/j.molcel.2014.01.003

Tili E, Michaille JJ, Costinean S, Croce CM (2008) MicroRNAs, the immune system and rheumatic disease. Nat Clin Pract Rheumatol 4: 534-541. http://dx.doi.org/10.1038/ncprheum0885

Tsutsumi A, Kawamata T, Izumi N, Seitz H, Tomari Y (2011) Recognition of the pre-miRNA structure by Drosophila Dicer-1. Nat Struct Mol Biol 18: 1153-1158. http://dx.doi.org/10.1038/nsmb.2125

Tyczewska A, Kurzynska-Kokorniak A, Koralewska N, Szopa A, Kietrys AM, Wrzesinski J, Twardowski T, Figlerowicz M (2011) Selection of RNA oligonucleotides that can modulate human dicer activity in vitro. Nucleic Acid Ther 21: 333-346. http://dx.doi.org/10.1089/ nat.2011.0304

Vermeulen A, Behlen L, Reynolds A, Wolfson A, Marshall WS, Karpilow J, Khvorova A (2005) The contributions of dsRNA structure to Dicer specificity and efficiency. RNA 11: 674-682. http://dx.doi. org/10.1261/rna.7272305

Wostenberg C, Lary JW, Sahu D, Acevedo R, Quarles KA, Cole JL, Showalter SA (2012) The role of human Dicer-dsRBD in processing small regulatory RNAs. PLoS One 7: e51829. http://dx.doi. org/10.1371/journal.pone.0051829

Yan KS, Yan S, Farooq A, Han A, Zeng L, Zhou MM (2003) Structure and conserved RNA binding of the PAZ domain. Nature 426: 468-474. http://dx.doi.org/10.1038/nature02129

Zhang H, Kolb FA, Brondani V, Billy E, Filipowicz W (2002) Human Dicer preferentially cleaves dsRNAs at their termini without a requirement for ATP. EMBO J 21: 5875-5885

Zhang H, Kolb FA, Jaskiewicz L, Westhof E, Filipowicz W (2004) Single processing center models for human Dicer and bacterial RNase III. Cell 118: 57-68. http://dx.doi.org/10.1016/j.cell.2004.06.017

Zisoulis DG, Kai ZS, Chang RK, Pasquinelli AE (2012) Autoregulation of microRNA biogenesis by let-7 and Argonaute. Nature 486: 541-544. http://dx.doi.org/10.1038/nature11134 